\title{
Granuloma aséptico facial idiopático
}

\author{
Luz Belén Zambrano Centeno ${ }^{a}$, Carlos Gómez González ${ }^{\mathrm{b}}$, Mercedes Rojo López ${ }^{\mathrm{c}}$ \\ y María Luisa Alonso Pacheco ${ }^{d}$
}

\begin{abstract}
${ }^{a}$ Médico de Familia.
Centro de Salud Puente del Arzobispo. Toledo (España). ${ }^{\mathrm{b}}$ M.I.R. de Medicina Familiar y Comunitaria. Centro de Salud Talavera Centro. Talavera de la Reina. Toledo (España).

${ }^{\mathrm{c}}$ Máster en Medicina de Urgencias y Emergencias. SUMMA 112. San Martín de Valdeiglesias. Madrid (España). dDermatóloga. Servicio de Dermatología. Hospital La Paz. Madrid (España).
\end{abstract}

Correspondencia:

Luz Belén Zambrano Centeno.

Correo electrónico:

bezamce@yahoo.es

Recibido el 11 de junio de 2014 Aceptado para su publicación el 14 de agosto de 2014.

\begin{abstract}
RESUMEN
El Granuloma Aséptico Facial Idiopático (GAFI) es un proceso dermatológico propio de la edad pediátrica, caracterizado por la presencia de un nódulo inflamatorio adquirido de larga evolución en la piel facial, sin dolor ni calor local. Su localización habitual es en la mejilla, en el triángulo que forma el ángulo externo del ojo, el lóbulo de la oreja y la comisura labial. Se han postulado varias hipótesis respecto a su etiología, como su relación con traumatismos sutiles o picaduras de insecto o bien se trate de un residuo embriológico o, la más aceptada en la actualidad, de una forma peculiar de manifestación de la rosácea en la infancia. Si bien en la literatura solo se han reportado 45 casos, algunos autores señalan que puede tratarse de un proceso poco conocido y no tan infrecuente en la edad infantil. Consideran así mismo que su apariencia clínica, localización y evolución características pueden ser suficientes para su diagnóstico, evitando así intervenciones diagnósticas y terapéuticas agresivas en una edad tan sensible al dolor, y con la posibilidad de secuelas cicatriciales en la cara. Presentamos un nuevo caso de GAFI, manejado de un modo conservador, tras ser diagnosticado a tenor de sus manifestaciones clínicas y evolutivas.
\end{abstract}

Palabras Clave. Granuloma. Rosácea. Atención Primaria de Salud.

\section{ABSTRACT}

\section{Idiopathic facial aseptic granuloma}

The idiopathic facial aseptic granuloma (IFAG) is a cutaneous condition characteristic in the pediatric age which is characterized by an acquired inflammatory painless nodule of longterm evolution in the facial skin and presents no local heat. It usually appears on the cheeks, in the triangle formed by the external angle of the eye, the earlobe and the labial commissure. Several hypothesis have been postulated on its etiology: its appearance could be related to a slight injury or an insect bite or could be an embryological remnant. The most widely accepted hypothesis is that it could be a particular manifestation of rosacea in infants. Although only 45 cases have been reported in the literature, some authors point out that it could be a little known process and not so uncommon in the pediatric age. It is also considered that its clinical characteristic aspect, localization and evolution could be sufficient for correct diagnosis, thus avoiding invasive diagnostic interventions and aggressive therapies in such a sensitive age to pain and with the possibility to leave scars in the child's face. The present is a new case of IFAG handled in a conservative way after diagnosis based on its evolutional and clinical manifestations.

Key words: Granuloma. Rosacea. Primary Health Care.

\section{INTRODUCCIÓN}

El Granuloma Aséptico Facial Idiopático (GAFI) es una afectación cutánea definida por la presencia de un nódulo firme o elástico, eritematoso o violáceo que se asemeja a un absceso. Se diferencia de este por ser indoloro, no fluctuante y frío al tacto ${ }^{1}$. Afecta por igual a ambos sexos, con edades comprendidas entre los 8 meses y los 13 años, con una edad media de 4 $a_{n ̃ o s}{ }^{1,2}$. Aunque puede alcanzar $2,5 \mathrm{~cm}$ de diámetro, su tamaño medio se sitúa en $1 \mathrm{~cm}^{2-6}$. La duración del nódulo antes de la primera visita varía de 1

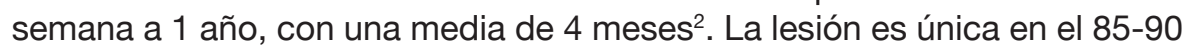
$\%$ de los casos y se localiza generalmente en la mejilla, si bien en ocasiones puede hacerlo en la proximidad de los párpados y con morfología similar 
a un chalazion ${ }^{1-4}$. Fue descrito por primera vez en Francia en 1999, bajo la denominación de "Pyodermite froide du visage"1. El diagnóstico del GAFI es clínico, aunque pruebas complementarias como la ecografía y la biopsia cutánea pueden sugerirlo o confirmarlo, respectivamente.

\section{CASO CLÍNICO}

Niña de 7 años sin antecedentes de interés remitida desde su centro de atención primaria por presentar una lesión en la mejilla derecha, algo pruriginosa y dolorosa, que no había mejorado tras tratamiento oral con amoxicilina/clavulánico, pautado prácticamente desde su inicio durante las dos semanas anteriores. A la exploración mostraba en la mejilla derecha un nódulo eritematovioláceo, frío y blando al tacto, bien delimitado, de 1,5 cm de diámetro (figura 1). No se palpaban adenomegalias regionales, aunque sí una leve queratosis pilar en la piel de las mejillas.

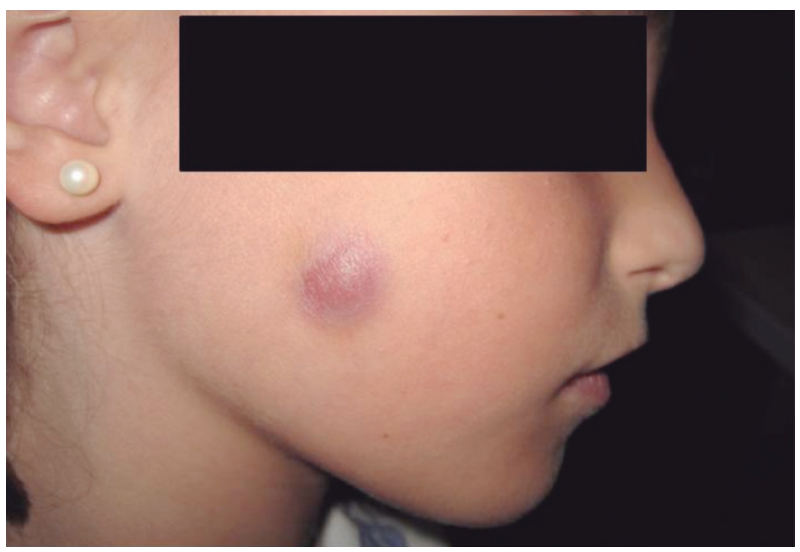

Figura 1. Nódulo eritematovioláceo bien delimitado en el área convexa de la mejilla derecha

Ante la sospecha clínica de GAFI, e informados los padres sobre la benignidad del proceso, se consensuó con ellos no realizar biopsia cutánea y pautar seguimiento periódico, junto con terapia con metronidazol gel por la noche. Dos semanas más tarde se produjo el drenaje espontáneo de un material sanguino-purulento desde el centro de la lesión, con posterior resolución progresiva del nódulo en el transcurso de unas 6 semanas. Los cultivos para bacterias, hongos y micobacterias del exudado de drenaje resultaron ser negativos. No obstante, tras la resolución de la lesión nodular, persistieron unas telangiectasias residuales en el área afecta, que se han ido atenuando lentamente durante los 10 meses de seguimiento (figura 2). Aconsejamos revisiones a la paciente hasta la resolución com- pleta del proceso y alertamos sobre la necesidad de consultar ante la aparición de síntomas o signos clínicos sugerentes de rosácea ocular (sequedad o enrojecimiento ocular, blefaritis, chalazion, fotofobia, pérdida de agudeza visual).

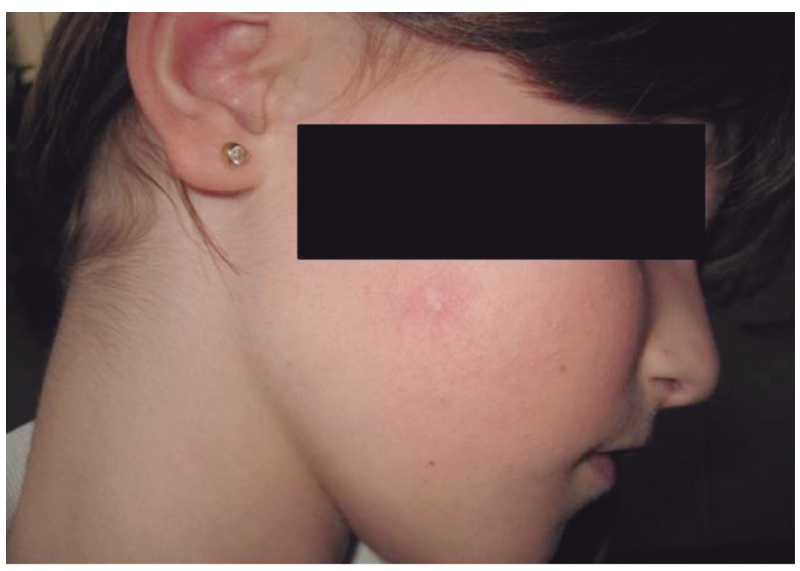

Figura 2. Telangiectasias residuales a los 10 meses

\section{DISCUSIÓN}

En los casos de GAFI referidos en la literatura no se han encontrado historia familiar o factores predisponentes asociados a esta entidad, pero sí se la ha relacionado de forma reiterada con la rosácea infantil. Así, un reciente estudio epidemiológico multicéntrico francés en 38 pacientes diagnosticados previamente de GAFI, demostró que un $42 \%$ de los niños asociaron desde el inicio o desarrollaron criterios de rosácea (tabla 1) en un periodo de seguimiento medio de 4 años, alcanzando el $83 \%$ en aquellos que tenían más de una lesión cutánea. Además, un $75 \%$ de los casos con criterios de rosácea infantil fueron diagnosticados también de rosácea ocular. Señalan así los autores que los niños con GAFI tienen un alto riesgo de desarrollar rosácea, sobre todo a nivel ocular, y que deben ser evaluados en este sentido por un oftalmólogo una vez al año'.

El examen con ultrasonido muestra una lesión dérmica bien demarcada, sólida e hipoecogénica, sin depósitos de calcio ${ }^{1-3,5}$. La histología objetiva un granuloma inflamatorio en la dermis superficial y profunda, a veces bien delimitado, con linfocitos, histiocitos y neutrófilos, así como células gigantes multinucleadas entremezcladas o en el centro de la lesión ${ }^{1-3,6}$. También se han descrito hallazgos de foliculitis granulomatosa ${ }^{3}$. Los exámenes directos y cultivos para bacterias, micobacterias y hongos, así como las improntas para tinción e identificación de leishmanias, son negativos. Los principales 


\begin{tabular}{c|l}
\hline 1 & Flushing facial con eritema permanente o recurrente \\
\hline 2 & Telangiectasias faciales sin otra enfermedad causal \\
\hline 3 & Pápulas o pústulas, con ausencia de comedones y microquistes \\
\hline 5 & Localización preferencial de las lesiones en la convexidad de la cara \\
& $\begin{array}{l}\text { Manifestaciones oculares (al menos una): } \\
\text { - Chalazion recurrente } \\
\end{array}$ \\
& - Quereremia conjuntival \\
\hline
\end{tabular}

Tabla 1. Criterios diagnósticos de rosácea infantil (debe cumplir al menos dos criterios)

diagnósticos diferenciales incluyen a las piodermitis localizadas, como el forúnculo, el acné noduloquístico paucisintomático, el pilomatrixoma, el botón de Oriente, la botriomicosis y el granuloma piogénico ${ }^{2,3,7}$.

No se ha referido drenaje espontáneo de la lesión, como en nuestro caso, pero sí la exudación de material sanguino-purulento tras mínima incisión en su superficie ${ }^{2}$ o en la mucosa oral subyacente a la misma $^{7}$. El aumento brusco de tamaño y la aparición de dolor se ha relacionado con la presencia de una posible sobreinfección bacteriana ${ }^{2}$. No sabemos si el dolor que aquejaba nuestra paciente pudo estar relacionado con esta eventualidad, si bien ni la sintomatología ni el aspecto de la lesión parecieron haberse modificado con la terapia antibiótica administrada.

Aunque la lesión suele persistir durante meses tiende a desaparecer de manera espontánea, sin dejar cicatrices significativas y sin recidivar, en el curso medio de un año ${ }^{2,8}$. Por este motivo, la abstención terapéutica parece consolidarse como una opción adecuada para su manejo ${ }^{6,8}$. No se ha demostrado eficacia de los tratamientos tópicos habituales utilizados para la rosácea, pero en la experiencia de algunos autores el tratamiento por vía oral con metronidazol (20 mg/kg/día al menos 4 semanas) o claritromicina (30 mg/kg/día 2-8 semanas) puede producir mejorías espectaculares ${ }^{1-3,8}$. Otros propugnan la realización de una mínima incisión para el drenaje en la superficie de la lesión, con el fin de acelerar así la curación de la misma ${ }^{3,7}$. La extirpación quirúrgica se ha llevado a cabo en casos persistentes, que no habían involucionado tras 1-2 años de seguimiento, para asegurar el diagnóstico con estudio histopatológico ${ }^{2}$. Aunque se menciona la presencia de manchas rosadas residuales tras la resolución del nódulo ${ }^{2-5}$, telangiectasias como tales y como en nuestra enferma no se han referido en la literatura. Pensamos que estas apoyarían la hipótesis nosológica de la rosácea.

Como conclusión, presentamos un nuevo caso de GAFI en el que la edad de la paciente, así como la apariencia clínica, localización y evolución características de la lesión, en ausencia de adenopatías y de síntomas constitucionales, fueron suficientes para la realización del diagnóstico. La presencia de telangiectasias residuales y la localización inicial de la lesión en el área convexa de la mejilla nos indujeron a situar el proceso en el espectro de una posible rosácea infantil, y a indicar un seguimiento de la niña especialmente orientado al diagnóstico precoz de una rosácea ocular.

\section{BIBLIOGRAFÍA}

1. Prey S, Ezzedine K, Mazereeuw-Hautier J, Eschard C, Barbarot S, Boralevi $F$ et al. IFAG and childhood rosacea: a possible link? Pediatr Dermatol. 2013; 30 (4): 429-32.

2. Boralevi F, Léauté-Labrèza $C$, Lepreux $S$, Barbarot $S$, Mazereeuw-Hautier J, Eschards $\mathrm{C}$ et al. Idiopathic facial aseptic granuloma: a multicentre prospective study of 30 cases. Br J Dermatol. 2007; 156 (4): 705-8.

3. Neri I, Raone B, Dondi A, Misciali C, Patrizi A. Should idiopathic facial aseptic granuloma be considered granulomatous rosacea? Report of three pediatric cases. Pediatr Dermatol. 2013; 30 (1): 109-11.

4. Al Dhaybi R, McCuaig C, Kokta V. A periocular nodule in a child. Clin Exp Dermatol. 2011; 36 (1): 105-6.

5. Baroni A, Russo T, Faccenda F, Piccolo V. Idiopathic facial aseptic granuloma in a child: a possible expression of childhood rosacea. Pediatr Dermatol. 2013; 30 (3): 394-5.

6. Hiraldo-Gameroa A, Vera-Casaño A, Sanz-Trélles A. Granuloma aséptico facial idiopático. Actas Dermosifiliogr. 2013; 104 (7): 635-6.

7. Roul S, Léauté-Labrèze C, Boralevi F, Bioulac-Sage P, Maleville J, Taïeb A. Idiopathic aseptic facial granuloma (pyodermite froide du visage): a pediartric entity? Arch Dermatol. 2001; 137 (9): 1253-5.

8. Chamaillard M, Mortemousque B, Boralevi F, Marqués C, Aitali F, Taïeb A et al. Cutaneous and ocular signs of childhood rosacea. Arch Dermatol. 2008; 144 (2): 167-71. 